NOTA

\title{
AVALIAÇÃO QUANTITATIVA DA MASSA FIBROSA E VAZIOS EM COLMOS DE BAMBU (1)
}

\author{
ANISIO AZZINI $(2,4)$, JOSÉ MAXIMILIANO MATTO GROSSO BORGES (3), \\ DIRCEU CIARAMELLO (2) $\otimes$ ANTONIO LUIZ DE BARROS SALGADO (2)
}

\section{RESUMO}

Em colmos de Bambusa tuldoides 'Munro, Bambusa vulgaris Schrad Dendrocalamus giganteus Munro, determinaram-se as dimensóes quanto à alltura e ao diâmetro basal, além dos teores de nó, massa fibrosa e vazios ("ocos") dos internódios. Os teores de nó, em relaçáo ao peso úmido do colmo, foram de $6,32,11,70$ e $13,41 \%$, respectivamente, para $B$. tuldoides, $D$. gigantous $e B$. vulgaris. Em volume, os teores de massa fibrosa no colmo de bambu variaram de $46,09 \%$. para $D$. giganteus, a $61,19 \%$, para B. tuldoides, sendo de $53,32 \%$ o valor intermediário para B. vulgaris. Este estudo foi efetuado no Centro Experimental de Campinas (IAC) em 1988.

Termos de indexaçąo: bambu, massa fibrosa, no, internódio.

\section{ABSTRACT \\ QUANTITATIVE EVALUATION OF FIBROUS MATERIAL AND HOLLOWS OF BAMBOO CULMS}

Culms of Bambusa tuldoides Munro, Bambusa vulgaris Schrad and Dendrocalamus giganteus Munro, were studied and the following variables were determined: height and basal diameter, content of nodes, fibrous material and intemode hollows. The node contents, regarding the fresh weight, were $6.32,11.70$ and $13.41 \%$, respectively for $B$. tuldoides, $D$. giganteus and $B$. vulgaris. Regarding the culm volume, the fibrous material contents ranged from $46.09 \%$ for $D$. giganteus to $61.19 \%$ for $B$. tuldoides. The intermediate value was $53.32 \%$ for $B$. vulgaris. This study was carried out in 1988 at the Instituto Agronómico de Campinas in State of São Paulo, Brazil.

- Index terms: bamboo, fibrous material, node, internode.

\footnotetext{
(1) Enviado para publicação em 28 de junho de 1989 e aceito em 6 de abril de 1990.

(2) Seçăo de Plantas Fibrosas, Instituto Agronómico (IAC), Caixa Postal 28, 13001, Campinas (SP).

(3) Engenheiro-Agrónomo, Estagiário da Seçáo de Plantas Fibrosas.

- (4) Com bolsa de pesquisa do CNPq.
} 
O interesse industrial do bambu como matéria-prima celulósica para produção de papel está intimamente ligado às caracteristicas qualitativas e quantitativas dos nós e internódios, que são os componentes básicos dos colmos. Os nós, com propriedades fisicas, químicas e anatômicas diferenciadas dos internódios nomalmente são excluíclos do processamento industrial como rejeitos.

O objetivo básico do presente estudo foi quantificar a massa fibrosa dos colmos de bambu (nós e internódios) e os vazios ("ocos") dos internódios, em três espécies de bambu, $B$. tuldoides, $B$. vulgaris e $D$. giganteus, consideradas na prática como sendo, respectivamente, de porte baixo, médio e alto.

\section{Material e Métodos}

Estudaram-se três espécies de bambu (Bambusa tuldoides Munro, Bambusa vulgaris Schrad e Dendrocalamus giganteus Munro), consideradas, respectivamente, de porte baixo, médio e alto, mantidas em coleçāo no Centro Experimental de Campinas (IAC). Para cada espécie, utilizaram-se quatro touceiras, retirando-se de cada uma três colmos com cerca de três anos de idade. Em todo colmo, após a determinação da altura e do diâmetro basal, retirou-se um nó e o internódio adjacente, localizados a $25 \%$ de sua altura.

A densidade básica do nó, do internódio e úo conjunto nó/internódio foi determinada pela relação entre o peso seco e seu volume úmido, conforme métocio nāo destrutivo citado por HALWAKD \& SANCHES (1975). O teor de nó foi obtido pela relação percentual entre os pesos úmidos do nó e do conjunto nó/internódio. A diferença do teor de nó para 100 forneceu indiretamente o de internódio. Determinaram-se os volumes de massa fibrosa do nó, do internódio e do conjunto nó/intemódio em funçăo do comprimento e diâmetros intemos e externos das amostras e seus teores percentuais, em relação ao volume do colmo. $O$ teor de vazios nos internódios foi obtido pela relação percentual entre o volume de vazios do internódio e o volume do conjunto nó/internódio.

\section{Resultados e Discussāo}

Os dados referentes à altura e ao diâmetro basal dos colmos são apresentados no quadrọ 1. Quanto à altura, não houve diferenças significativas entre $B$. tuldoides $(12,90 \mathrm{~m})$ e $B$. vulgaris $(12,70 \mathrm{~m})$, ambos inferiores a $D$. giganteus $(20,90 \mathrm{~m})$. Para o diâmetro basal, houve perfeita diferenciaçāo entre as espécies: $4,38 \mathrm{~cm}, B$. tuldoides; $7,88 \mathrm{~cm}, B$. vulgaris, e $15,71 \mathrm{~cm}, D$. giganteus. Esses dados sugerem que o diâmetro basal foi a característica morfológica mais indicada para classificar essas espécies quanto ao porte baixo (B. tuldoides), médio (B. vulgaris) e alto (D. giganteus). Na prática, a classificação das espécies de bambu quanto ao porte é muito importante, sobretudo para se estabelecer a densidade de plantio em funçāo da espécie. 
QUADRO 1. Altura e diâmetro basal dos colmos de bambu (')

\begin{tabular}{|c|c|c|c|}
\hline \multirow{2}{*}{ Espécie } & \multicolumn{2}{|c|}{ Altura (2) } & \multirow{2}{*}{$\begin{array}{c}\text { Diâmetro } \\
\text { basal }\end{array}$} \\
\hline & Máxima & Útil & \\
\hline
\end{tabular}

\begin{tabular}{|c|c|c|c|}
\hline \multirow[b]{2}{*}{ Bambusa tuldoides } & \multicolumn{2}{|c|}{$\mathrm{m}$} & $\mathrm{cm}$ \\
\hline & $12,90 \mathrm{~b}$ & $8,02 b$ & $4,38 \mathrm{c}$ \\
\hline Bambusa vulgaris & $12,70 b$ & $9,50 \mathrm{~b}$ & $7,88 \mathrm{~b}$ \\
\hline Dendrocalamus giganteus & $20,90 a$ & $17,56 a$ & $15,71 \mathrm{a}$ \\
\hline dms (Tukey a $5 \%$ ) & 1,79 & 1,91 & 0,95 \\
\hline CV (\%) & 11,53 & 16,32 & 10,23 \\
\hline
\end{tabular}

(1) Médias de doze colmos.

(2) Altura útil: considerada, empiricamente, como sendo o comprimento do colmo até o diámetro mínimo de $3 \mathrm{~cm}$.

No quadro 2, aparecem os valores da densidade básica dos nós, intemódios e do conjunto nó/intemódio. Para os nós, a menor densidade básica foi observada nos colmos de B. tuidoides $\left(0,570 \mathrm{~g} / \mathrm{cm}^{3}\right)$; os valores de $B$. vulgaris $\left(0,716 \mathrm{~g} / \mathrm{cm}^{3}\right)$ e $D$. giganteus $\left(0,729 \mathrm{~g} / \mathrm{cm}^{3}\right)$ não se diferenciaram estatisticamente. No internódio, houve diferença significativa apenas entre $B$. tuldoides $\left(0,530 \mathrm{~g} / \mathrm{cm}^{3}\right)$ e $D$. giganteus $\left(0,663 \mathrm{~g} / \mathrm{cm}^{3}\right)$. O conjunto nó/internódio apresentou variação semelhante à do internódio, sendo a densidade básica dos colmos de $B$. tuldoides $\left(0,533 \mathrm{~g} / \mathrm{cm}^{3}\right)$ inferior à do $D$. giganteus $\left(0,688 \mathrm{~g} / \mathrm{cm}^{3}\right)$. A densidade básica dos nós apresentou uma tendência de ser mais elevada que a dos intemódios, podendo ser essa a principal razão de os nós apresentarem maior dificuldade de deslignificação durante o processamento do bambu para produção de fibras celulósicas para papel.

As relaçōes entre a densidade básica do colmo e as caracteristicas tecnológicas das fibras celulósicas não são perfeitamente conhecidas para o bambu, contrastando com as espécies arbóreas. Para as madeiras, uma elevaçăo na densidade básica corresponde a um aumento no rendimento de conversão em fibras celulósicas e elevação na resistência ao rasgo do papel (MACHADO et al., 1975). 
QUADRO 2. Densidade básica do nó, internódio e conjunto nófinternódio em colmos de bambu ( $\left.{ }^{1}\right)$

\begin{tabular}{lccc}
\hline Espécie & Nó & Internodio & Nó/internódio \\
\hline & & $\mathrm{g} / \mathrm{cm}^{3}$ & $\ldots$ \\
\cline { 2 - 4 } Bambusa tuldoides & $0,570 \mathrm{~b}$ & $0,530 \mathrm{~b}$ & $0,533 \mathrm{~b}$ \\
Bambusa vulgaris & $0,716 \mathrm{a}$ & $0,584 \mathrm{ab}$ & $0,594 \mathrm{ab}$ \\
Dendrocalamus giganteus & $0,729 \mathrm{a}$ & $0,663 \mathrm{a}$ & $0,688 \mathrm{a}$ \\
\hline dms (Tukey a 5\%) & 0,100 & 0,105 & 0,100 \\
CV $(\%)$ & 16,95 & 17,41 & 16,67 \\
\hline
\end{tabular}

(1) Médias de doze colmos.

O quadro 3 apresenta os teores de nó e internódio em relação ao peso úmido do colmo. Nos colmos de $B$. tuldoides, o teor de nó $(6,32 \%)$ foi menor que nos de $D$. giganteus $(11,70 \%)$ e B. vulgaris $(13,41 \%)$, cujos valores nāo apresentaram variaçōes significativas. Como o teor de internódio foi calculado como um complemento do teor de nó para 100 , seu valor, conseqüentemente, foi maior nos colmos de $B$. tuldoides $(93,68 \%)$ em comparação com $D$. giganteus $(88,30 \%)$ e B. vulgaris $(86,59 \%)$.

No processamento convencional dos cavacos de bambu, visando-se à produçāo de fibras celulósicas para papel, os nós normalmente permanecem mais lignificados que os internódios, sendo retirados da linha de produção como rejeitos. Esse inconveniente tecnológico pode ser contornado, procedendo-se à separação dos nós por peneiramento. Em função de sua constituição anatômica mais rigida, os nós permanecem agregados após a transformaçāo mecânica dos colmos em cavacos, sendo retirados na peneira.

QUADRO 3. Percentagem em peso, do nó e do internódio em colmos de bambu (1)

\begin{tabular}{|c|c|c|}
\hline Espécie & No & internódio \\
\hline Bambusa tuldoides & $6,32 b$ & $93,68 a$ \\
\hline Bambusa vulgaris & $13,41 a$ & $86,59 b$ \\
\hline Dendrocalamus giganteus & $11,70 \mathrm{a}$ & $88,30 \mathrm{~b}$ \\
\hline dms (Tukey a $5 \%$ ) & 2,08 & 2,08 \\
\hline $\mathrm{CV}(\%)$ & 19,83 & 2,32 \\
\hline
\end{tabular}

(1) Médias de doze colmos. 
No quadro 4, aparecem os teores de massa fibrosa do nó, internódio, conjunto nó/internódio e vazios dos intemódios, em relação ao volume do colmo. Os teores de nó foram de $5,91,10,70$ e $12,01 \%$, respectivamente, para $B$. tuldoides, $D$. giganteus e $B$. vulgaris, não havendo diferenças significativas entre as duas últimas espécies.

Para o internódio, os teores variaram significativamente de $35,59 \%$ D. giganteus - a $55,28 \%$ - B. tuldoides, sendo de $41,31 \%$ o valor intermediário - B. vulgaris. Os teores de conjunto nó/internódio apresentaram variaçōes semeIhantes às dos internodiò com $61,19,53,32$ e $46,09 \%$, respectivamente, para $B$. tuldoides, $B$. vulgaris e $D$. giganteus. Esses dados mostram que a massa fibrosa nos colmos de bambu variaram com o diâmetro do colmo, sendo maior nos de menor diâmetro. A afirmação de UEDA (1968), de que a massa fibrosa dos colmos de bambu tropicais representa $2 / 3$ do seu volume, não foi confirmada.

Os vazios existentes no interior dos internódios foram maiores nos colmos de $D$. giganteus $(53,91 \%)$ que nos de $B$. vulgaris $(46,68 \%)$ e $B$. tuldoides $(38,81 \%)$.

QUADRO 4. Percentagem em volume do nó, internódio, conjunto nó/internódio e vazio em colmos de bambu (1)

\begin{tabular}{|c|c|c|c|c|}
\hline Espécie & Nó & Internódio & Nó/internódio & Vazio \\
\hline & & - & & - \\
\hline Bambusa tuldoides & $5,91 b$ & $55,28 a$ & $61,19 a$ & $38,81 a$ \\
\hline Bambusa vulgaris & $12,01 \mathrm{a}$ & $41,31 b$ & $53,32 b$ & $46,68 \mathrm{~b}$ \\
\hline Dendrocalamus giganteus & $10,70 a$ & $35,59 \mathrm{c}$ & $46,09 \mathrm{C}$ & $53,91 \mathrm{c}$ \\
\hline dms (Tukey a $5 \%$ ) & 2,18 & 5,55 & 5,54 & 5,56 \\
\hline CV $(\%)$ & 22,84 & 11,90 & $10,31 *$ & 11,31 \\
\hline
\end{tabular}

(1) Médias de doze colmos.

\section{CONCLUSÕES}

1. O diâmetro basal dos colmos de bambu foi a dimensão mais adequada para classificar as espécies estudadas quanto ao porte baixo (B. tuldoides), médio (B. vulgaris) e alto (D. giganteus);

2. O menor teor de nó foi observado nos colmos de B. tuldoides, tanto em relação ao peso úmido do colmo $(6,32 \%)$ como em relação ao seu volume $(5,91 \%)$; 
3. Em volume, os colmos de B. tuldoides apresentaram maior teor de massa fibrosa $(61,19 \%)$ que os colmos de $B$. vulgaris $(53,32 \%)$ e $D$. giganteus $(46,09 \%)$.

\section{REFERÊNCIAS BIBLIOGRÁFICAS}

HALWARD, A. \& SANCHES, C. Métodos de ensaios nas indústrias de celulose e papel. São Paulo, Editora Brusco, 1975. 457p.

MACHADO, F.لد.; GOMIDE, J.L.; CAMPOS W.O. \& CAPITANI, L.R. Estudo comparativo das madeiras de Eucaliptus torelliana e Eucaliptus grandis para produçăo de polpa Kraft. O Papel, Săo Paulo, 48(8):56-60, 1987.

UEDA, K. Culture of bamboo as raw material. Kyoto, Association of Overseas Technical Scholar-Ship, 1968. $47 p$. 